\title{
Origin and development of homoiothermy: A case study of avian energetics
}

\author{
Valery M. Gavrilov \\ Department of Vertebrates Zoology and Skadovsky Zvenigorod Biological Station, Moscow State University, Moscow, Russia \\ Email: vmgavrilov@mail.ru
}

Received 11 June 2013; revised 12 July 2013; accepted 30 July 2013

Copyright (C) 2013 Valery M. Gavrilov. This is an open access article distributed under the Creative Commons Attribution License, which permits unrestricted use, distribution, and reproduction in any medium, provided the original work is properly cited.

\begin{abstract}
The study is based on the results of the integrated measurement of the energy expenditure at rest and common activity in birds belonging to various systematic groups. Homeothermy has formed in birds and mammals independently and in different geological ages. However, in both groups it originated as a side effect of selection for aerobic metabolism improvement that provided a higher level of activity. Advantages of having high and stable body temperature, which were inevitably related with metabolism intensification, led to development of thermoregulatory adaptations such as fur and feathers. This made it possible to retain the metabolically generated heat and reduce heat absorption in hot environments. Emergence of homeothermy with aerobic supply of motion activity, possibilities to regulate the level of metabolism and thermal conductance, has opened a lot of opportunities for homoeothermic animals. Achieving such a level of energy utilization allowed them to maintain activity for a longer time, while its sensory support led to complication and diversification of birds' behavioral repertoire (as well as that of mammals) facilitating the conquest of almost entire part of the biosphere that was suitable for living. This process was favored by the development of nurturing and passing on the information, collected throughout the life, to new generations. Formation of high levels of aerobic metabolism in birds and mammals was proceeding in parallel among different groups of reptilian ancestors. The level of homeothermy, at which aerobic metabolism was able to maintain prolonged activity, developed in birds and mammals in different ways: they had got dissimilar partitioning of venous and arterial networks, erythrocytes with or without a cell nucleus, different lungs design — but, at that, similar minimum metabolic power and rather close body
\end{abstract}

temperatures which corresponded well to the environmental conditions on the Earth. Natural selection allowed animals with high energetic metabolism to increase their diversity and abundance, but only when homoeothermic animals could satisfy their demands for food resources, that had risen manifold. That happened in the middle of Cretaceous, in time with the appearance of angiosperms and expansion of related fauna of invertebrates.

Keywords: Basal Metabolism; Metabolism of Existence; Homoiothermy; Erythrocytes in Birds and Mammals; Aerobic Supply of Activity and Sensory Systems; Minimal Size; Parental Care

\section{INTRODUCTION}

Maintaining a constant body temperature over wideranging changes in ambient temperature is achieved in homeothermic animals by maintaining an equilibrium between heat loss and heat production. A physical interpretation of this phenomenon is not difficult if one examines the heat balance of a resting animal at low temperatures [1], but when one examines the heat balance of an active animal at high temperatures, this physical interpretation encounters a series of contradictions which as yet have not been eliminated.

Birds and mammals are two classes of higher vertebrates and both of them are Homoiotherms. The establishment of homoiothermy by birds and mammals during the Mesozoic is directly connected with the development of high activity, which is enabled by aerobic metabolism. Homoiothermy allowed them to broaden the behavioral repertoire and prolong the period of activity. In general, long term activity and endurance are the basic benefits of homoiothermy, which have given a selective advantage to birds and mammals [2]. This high aerobic metabolism allowed the behavioral patterns evolution in 
birds and mammals to reach such high levels. This evolution had to be based on the preceding or parallel evolution of metabolic systems which were capable to provide high activity. The basis of homoiothermy is in the combination of high heat production and low thermal conductance $[2,3]$.

The goal of this work was to propose a possible evolutionary and ecological scenario for the causes and conditions underlying the establishment of homoiothermy and the colonization of major ecological niches by homoiotherms. The paper is based on a set of experimental data on the energetics of the extant vertebrates, its theoretical substantiation, and an analysis of the relevant literature on the major events in the Mesozoic era.

This study utilizes the results of an integrated measurement of the energy expenditure at rest (assessed according to oxygen consumption) and common activity, i.e., the so called existence metabolism (assessed according to food consumption), as well as the energy expenditures in flight and at a maximal loading in birds belonging to various systematic groups that display considerable variations in their body sizes. The main attention was focused on clarifying the balance between the minimal metabolic capacity (basal metabolic rate, $B M R$ ) and other levels of energy expenditures, such as the standard (resting) metabolic rate and energy expenditures for the existence at different ambient temperatures $\left(T_{\mathrm{A}}\right)$. To estimate the maximal potential of birds in dissipating excess heat, we had to estimate the maximal and productive metabolic rates, as well as the energy expenditures for activity in various passerine and non-passerine species. Thus, this paper is an attempt to understand the scenario of homoiothermy origination from the standpoint of ecological energetics.

\section{ECOLOGICAL ENERGETICS OF RECENT VERTEBRATE ANIMALS AND ORIGIN OF HOMOIOTHERMY}

\subsection{The Hypotheses on the Reason and the Effects for Origin Homoiothermy in the Evolution}

The evolution of homoiothermy is usually discussed in the literature in the context of the advantages conferred by a stable body temperature (diurnal activity, enzyme functions, and tolerance to freezing) and thermoregulation [4-8]. Only some researchers pay attention to the increase in activity and fatigue resistance in homoiotherms [9-11]. The author also believes that thermoregulation is not the only selective advantage in the evolution of homoiothermy. Most likely, thermoregulation was not even the initial factor for the emergence of homoiothermy. Large extant reptiles are completely able to maintain a constant body temperature over $30^{\circ} \mathrm{C}$ under the conditions of an equable warm (subtropical) climate with small diurnal temperature variations [11,12]. This phenomenon is referred to as "inertial homoiothermy." Several biophysical models have been constructed to assess the possible body temperature of large dinosaurs $[13,14]$; their estimates are $30^{\circ} \mathrm{C}-47^{\circ} \mathrm{C}$. Advances in radioisotope research methods have allowed us to asses the body temperature in discovered extinct dinosaurs with various degrees of accuracy [15-20]. All of the isotopebased estimates for the body temperature of dinosaurs mainly fall into the range predicted by biophysical models. Nonetheless, the question on the true endothermy of dinosaurs remains open [17,19-21]. Most frequently, they are compared to contemporary crocodiles, which display certain attempts at endothermy. However, there is no final evidence that the metabolism of dinosaurs differed from the metabolism of extant reptiles [17,19-22]. Correspondingly, it is quite adequate to assume that the metabolism of extinct reptiles had no serious differences from the metabolisms of recent forms [9,11,23-30], despite the publications that imply such a difference (for example, [31]) that constantly appear in prestigious journals.

Differences in metabolism are naturally reflected in the food consumption, which remains in the reptiles by over one order of magnitude lower compared to mammals and birds. The establishment of homoiothermy was directly connected with the development of high activity, which is enabled by aerobic metabolism. This high aerobic metabolism made the evolution of complex behaveioral patterns feasible in birds and mammals. This evolution had to be based on the preceding evolution of metabolic systems capable of providing high activity. This resulted in an increased standard (resting) metabolic rate $(S M R)$, which became the minimal capacity level. The $S M R$ increased in order to enable even higher levels of work intensity in homoiotherms [2,9,11,32-38].

On the other hand, an increase in the energy expenditures cannot be subject to the positive control of natural selection, since an increase in the energy expenditures per se is disadvantageous for an organism. How, then, does natural selection control an increase in the capacity of energy metabolism? What are the ecological advantages gained by the animals with a high metabolism? What is the cost of possessing a high metabolism? And why did homoiothermy not emerge with lower body temperature? Researchers studying the ecological energetics of modern vertebrate groups face all of these questions and, in their answers, will give deeper insight into the origin of homoiothermy.

These tremendous ecological consequences failed to properly manifest for over 130 million years. The destruction of the bottom tiers of the ecological pyramid (the prime of angiosperms) was required for homoio- 
therms to colonize the new major niches formed at that time. The development of homoiothermy and homoiotherms is quite adequately described by models that simulate the development of crises in biological evolution by Zherikhin and Rautian [39-41].

\subsection{Terminology and Energetics of Homoiotherm Animals}

My long-term studies of the bird energetics allow me to develop a unified system of bioenergetic parameters, which describes thermal regulation and energy metabolism in many passerine and non-passerine species. These parameters have been analyzed as functions of ambient temperature $\left(T_{\mathrm{A}}\right)$, and bioenergetic models for various species have been developed. General trends in the influence of ambient temperature on the energetics of a homoiothermic animal were discussed in a certain form in my previous studies $[3,42,43]$. Analysis of experimental results and published data provided a basis for developing a generalized model reflecting the general pattern of dependence of energy parameters on ambient temperature in any of the species studied in this respect (Figure 1). The ability to regulate nonevaporative heat dissipation characterizes the level of development of the systems related to blood circulation and respiration. It is the functioning of these systems that should be used as a criterion for evaluating the physiological organization of an organism in terms of energetics. The amount of energy necessary for the functioning of these and other permanently operating systems (excretory, nervous, etc.) determines the minimum energy (basal) power level, or $B M R$. A fundamental finding is that all homoiotherms have the same limits of capacity for regulating heat dissipation at the same ambient temperature, since $\operatorname{tg} \angle \beta 1=$ $4 \operatorname{tg} \angle \beta 2$ (Figure 1). The establishment of $B M R$ is a result of the evolutionary development of systems related to circulation and respiration to the level at which heat dissipation at the same temperature can be regulated in a fourfold range without intensification of evaporation. $B M R$ provides for the maintenance of homoiothermy, but its origin is related to the necessity of maintaining a high activity level rather than to thermoregulation problems.

Moreover, $B M R$ determines other levels of energy expenditure, including maximum potential metabolism, maximum aerobic metabolism, and work output. These are the energy parameters that determine the ecological capacity of species and, therefore, their tolerance to environmental factors.

\subsection{General Elements for Energetic of Homoiotherm Animals}

The general patterns of the effect of ambient temperature on the energetics of a homoiotherm have been discussed
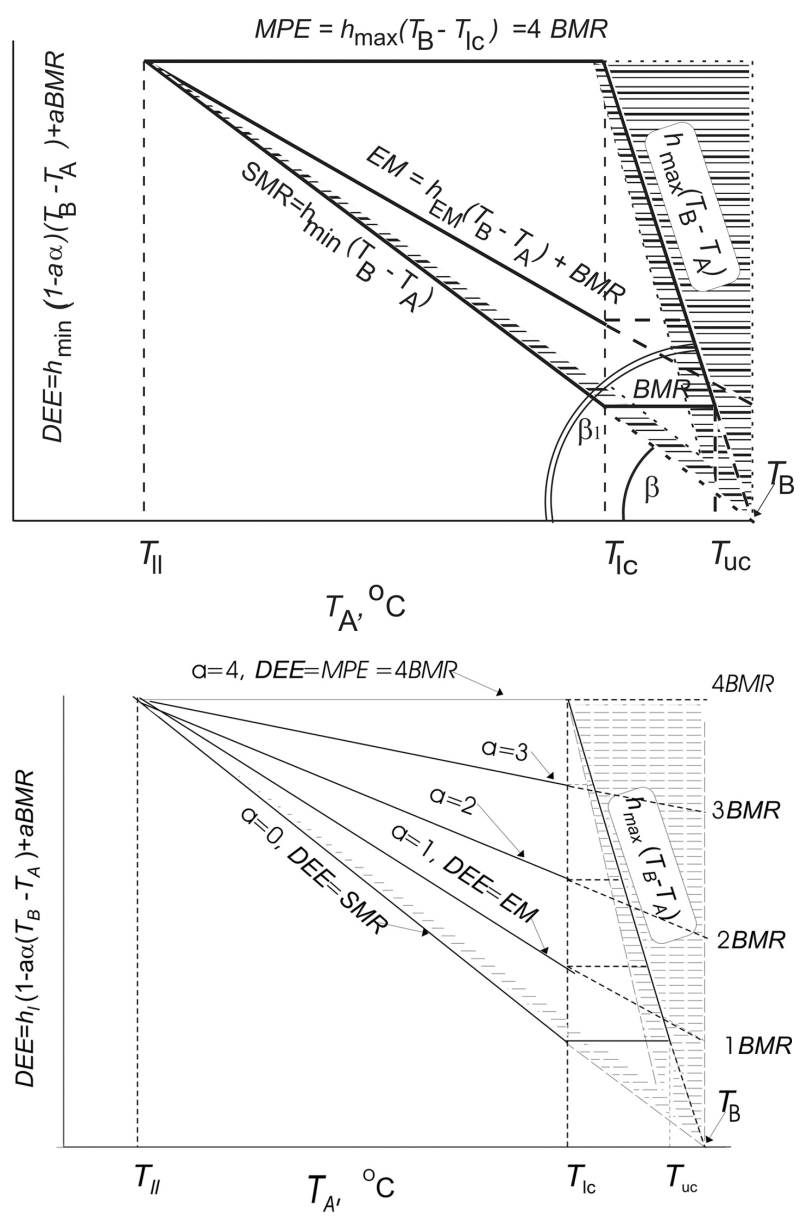

Figure 1. Top. Daily energy model of a homoiothermic animal based on experimentally determined dependencies of energy parameters on ambient temperature $\left(T_{\mathrm{A}},{ }^{\circ} \mathrm{C}\right): D E E=h_{\min }(1-$ $a \alpha)\left(T_{\mathrm{B}}-T_{\mathrm{A}}\right)+a B M R$, where $D E E$ is daily energy expenditure at activity level ( $a$, from 1 to 4 ) and ambient temperature; $h_{\min }$, the minimum degree of change in nonevaporative heat dissipation (thermal conductance) at rest $h_{\min }=\operatorname{tg} \angle \beta$; $h_{\max }$, the maximum degree of change in nonevaporative heat dissipation (thermal conductance) at rest $h_{\max }=\operatorname{tg} \angle \beta=4 \operatorname{tg} \beta ; \alpha=0.25$, coefficient of efficiency in converting metabolic into mechanical power (i.e., into work output); $T_{\mathrm{B}}$, body temperature $\left(40^{\circ} \mathrm{C}\right.$ in birds and $37^{\circ} \mathrm{C}$ in mammals); $B M R$, basal metabolic rate; $T_{\text {Ic }}$, lower critical temperature; $T_{\mathrm{uc}}$, upper critical temperature; $T_{1 \mathrm{ll}}$, lower limit of species temperature tolerance; $Q_{\min }=S M R=$ $h_{\min }\left(T_{\mathrm{B}}-T_{\mathrm{A}}\right)$, the minimum heat dissipation, or standard metabolic rate; $Q \max =h \max (T \mathrm{~B}-T \mathrm{~A})$, the maximum heat dissipation; $E M=h \mathrm{EM}(T \mathrm{~B}-T \mathrm{~A})+B M R$ existence metabolism; $a$, activity level (at $a=0, D E E=S M R$; at $a=1, D E E=E M$ ); $M P E=h_{\max }\left(T_{\mathrm{B}}-T_{\mathrm{lc}}\right)=4 B M R$ maximum potential existence metabolism. The hatched zone corresponds to nonevaporative heat dissipation. Bottom. Figure illustrates the significance of increase in the level of locomotor activity: the increase in the level of locomotor activity, a, strongly correlates with the increase in $D E E$ and with a decrease in the heat transfer coefficient during activity. $B M R$ is power ratings.

in various aspects in several publications by the author $[3,43-46]$. While working on this paper, all of the avail- 
able published energetic models for birds and mammals have been critically revisited. An analysis of the experimental and published data enabled a generalized model to be constructed for the energetics of homoiotherms, which specifies the general dependence of the major energetic parameters for any studied species on the ambient temperature (Figure 1). Here, $D E E=h_{\min }(1-a \alpha)\left(T_{\mathrm{B}}-\right.$ $\left.T_{\mathrm{A}}\right)+a B M R ; D E E$ is the daily energy expenditure at any level of activity $(a) ; h_{\min }$ is the minimal degree of nonevaporative heat loss (heat conductance) at rest $\left(h_{\min }=\right.$ $\tan \angle \beta h_{\max }$ ); $h_{\max }$ is the maximal degree of changes in nonevaporative heat loss (heat conductance) at rest ( $h_{\max }$ $=\tan \angle \beta 1=4 \tan \angle \beta) ; \alpha$ is the efficiency of the conversion of the metabolic capacity into mechanical (external) work $(\alpha=0.25) ; T_{\mathrm{B}}$ is the body temperature, which amounts to $40^{\circ} \mathrm{C}$ for birds and $37^{\circ} \mathrm{C}$ for mammals; $T_{\mathrm{A}}$ is the ambient temperature; $B M R$ is the basal metabolic rate; $T_{\mathrm{lc}}$ is the lower critical temperature; $T_{11}$ is the lower limit of specific temperature tolerance; $T_{\text {uc }}$ is the upper critical temperature; $Q_{\min }=S M R=h_{\min }\left(T_{\mathrm{B}}-T_{\mathrm{A}}\right)$ is the minimal heat loss or standard metabolic rate; $Q_{\text {max }}=h_{\max }\left(T_{\mathrm{B}}-T_{\mathrm{A}}\right)$ is the maximal heat loss; $E M=h_{\mathrm{EM}}\left(T_{\mathrm{B}}-T_{\mathrm{A}}\right)+B M R$ is the existence metabolism; $a$ is the activity level (at $a=0$, $D E E=S M R$ and, at $a=1, D E E=E M)$; and $M P E=$ $h_{\max }\left(T_{\mathrm{B}}-T_{\mathrm{lc}}\right)=4 B M R$ is the maximal potential existence metabolism. The hatched area corresponds to evaporative heat loss. The generalized mode for the energetics of homoiotherms demonstrates that two major characteristics, i.e., minimal and maximal heat losses, depend equally on the ambient temperature and theoretically reach zero (where they cross the abscissa at the same point) at an ambient temperature equal to body temperature (Figure 1). Thus, both the minimal $\left(Q_{\min }=S M R\right)$ and maximal $\left(Q_{\max }=M P E\right)$ heat losses precisely follow the Newton's law in the interpretation by Scholander. It is essential that the maximal heat loss without any considerable increase in the evaporation, which we introduce here and has been determined for a large number of species for the first time, also precisely corresponds to the Scholander model. Thus, the Scholander model is supplemented with the dependence of the maximal heat loss on the ambient temperature, so that it acquires finished form (Figure 1). Birds are able to dissipate any available amount of energy between two events of heat loss that converge at an ambient temperature equal to body temperature.

Homoiotherms always have a certain minimal level of heat production that results from the generation of heat during basic physiological processes, which can be never arrested. This minimal heat production level is referred to as the basal metabolic rate $(B M R)$ and represents the major minimal capacity of a homoiotherm (Figure 1).

The experimentally determined correlations between energetic parameters allow them to be represented in strict mathematical form, that is, as models.

Based on such measurements for all species, the dependences of energy expenditures at rest (SMR; at activity level $a=0$ ) and existence metabolism (EM; at activity level $a=1$ ) were obtained; in a general form, they are described by the following equations:

$$
\begin{gathered}
S M R=h_{1}\left(T_{\mathrm{B}}-T_{\mathrm{A}}\right), \\
E M=h_{E M}\left(T_{B}-T_{A}\right)+B M R,
\end{gathered}
$$

where $h_{1}$ is the temperature coefficient of increase in $S M R$ with a decrease in the ambient temperature $\left(T_{\mathrm{A}}\right)$ from the lower critical temperature $\left(T_{\mathrm{lc}}\right)$ or minimal thermal conductance of the bird body at rest; $h \mathrm{EM}$, the temperature coefficient of increase in the existence metabolism $(E M)$ with a decrease in the ambient temperature; $T_{\mathrm{B}}$, body temperature; and $B M R$, basal metabolic rate.

For the daily energy expenditure $(D E E)$ at any activity level $(a)$,

$$
D E E=h_{x}\left(T_{B}-T_{A}\right)+a B M R,
$$

where $h_{x}$ is heat conductance at a given activity level.

For the level of daily work output ( $D W O)$,

$$
D W O=\alpha D E E \text { or } D W O=h_{l}(1-a \alpha)\left(T_{B}-T_{A}\right)+a \alpha B M,
$$

where $h_{l}$ is the minimal heat loss at rest (at a zero activity) and $\alpha$ is the efficiency of the conversion of metabolic capacity into mechanical capacity (work output).

These results make it possible to objectively determine ecologically important zones of ambient temperatures, including optimal, upper and lower lethal, sublethal, and so on, according to the cross points of several energetic parameters.

\subsection{Functional Implication of Differences in Basal Metabolic Rate}

What have passerines gained from the elevation of $B M R$ ? For this study, I have critically reconsidered all models of bird and mammal energetics published in sources available to me. In particular, I have noted that, according to the observed relationship between energy parameters and ambient temperature, the maximum possible heat loss is equal to $16 B M R$, which coincides with the maximum value experimentally determined for maximum aerobic metabolism under exertion $(M A M=16$ $B M R$ ) in different animal groups. The oxygen consumption can increase more than 16-fold in both various passerine and non-passerine birds and mammals (Figure 2; $[2,32,33,44,47]$. Correspondingly, the energy expenditures for the highest activity reaches the same level of 16 metabolic capacities in various avian and mammalian 


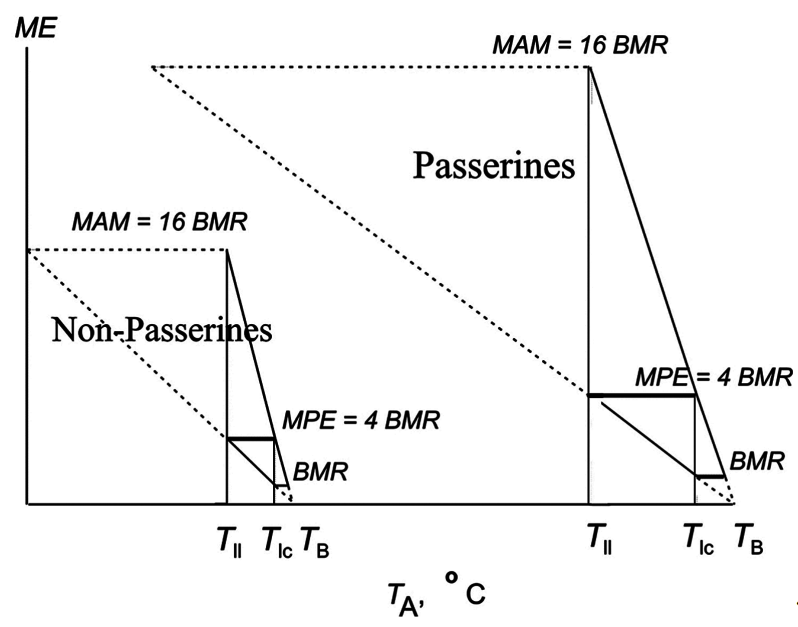

Figure 2. The scheme illustrates the functional implication of an increase in $B M R$ in the course of evolution or in a particular animal: the increase in $B M R$ strongly correlates with the increase in potential energy or maximal existence metabolism or maximum food energy ( $M P E$ equal to $4 B M R$ ). The increase in $B M R$ strongly correlates also with the increase in maximal aerobic metabolism which is equal to $16 B M R$ in different groups of animals.

species $[2,4,6,12,47-50]$. Reptilian lungs are also able to increase oxygen consumption by approximately 16 -fold. The oxygen can be consumed at this level for only a very short period, e.g., when escaping from a predator or chasing prey $[9,12,51]$.

\subsection{The Van-Goff's Law and Exigency of Homoiothermy}

During animal activity, large amounts of heat are generated and the body temperature rapidly increases, which is detrimental, since proteins are denatured at a high temperature. Correspondingly, perfect systems for dissipating heat are necessary to ensure the balance between heat production and loss. Van-Goff Case formulated the follow empirical law: when the temperature increases at 10 degree, the absolute symbol of the rate of biochemical elementary reaction increases in two-four folds. So the increase of the body temperature leads to the exponential increase of the biochemical reactions and to the strong thermal overload.

The major thermodynamic vital issue of the activity of poikilotherms is the dissipation of the heat generated during activity and during work. For this purpose, efficient mechanisms for heat dissipation are required, namely, a developed circulatory system and the ability to control the heat-insulating properties of body covers. This issue requires the development of the homoiothermy. The ancestors of birds and mammals avoided the negative consequences of the Van-Goff's law by making the constant body temperature.

\subsection{Resting Metabolic Rate in Different Animal Groups}

In all groups of poikilothermic vertebrates (fish, amphibian, and reptiles), the metabolic levels are almost equal. The allometric dependences of the reptilian, avian, and mammalian energetic characteristics demonstrate that the $S M R$ of reptilians heated to the body temperature of homoiotherms is one order of magnitude lower than the avian and mammalian BMRs in the level of energy expenditure. The high level of heat production, in combination with a low heat conductance of the body covers and the ability to change heat dissipation via the vasomotor response form the foundation of homoiothermy. The difference of one order of magnitude in the heat production between homoiotherms and poikilotherms exists even in the situation when the body temperature of poikilotherms reaches that of homoiotherms (Figure 3). However, the food consumption by reptiles in this case still remains one order of magnitude lower than in birds and mammals. The development of homoiothermy was directly connected with the development of high activity, which is ensured for by aerobic metabolism. This particular metabolism allowed for the evolution of complex behavior patterns in birds and mammals. This evolution required the preceding evolution of metabolic systems able to provide for a high level of activity. This resulted in an increased $S M R$, which became the minimal capacity level. The $S M R$ level had increased in order to enable one to achieve higher levels of work intensity in homoiotherms [2,9,11,32-37]. Birds are an advantageous model for studying the evolutionary aspects of animal energetics, although their ability to fly hinders the comparison of locomotor activity. The metabolism of nonpasserine birds corresponds to that of mammals, whereas the $B M R$ of the passerines is 1.3-1.5-fold higher. Figure 4 shows the $B M R$ dependences on body mass for different avian orders (the regressions were constructed ac-

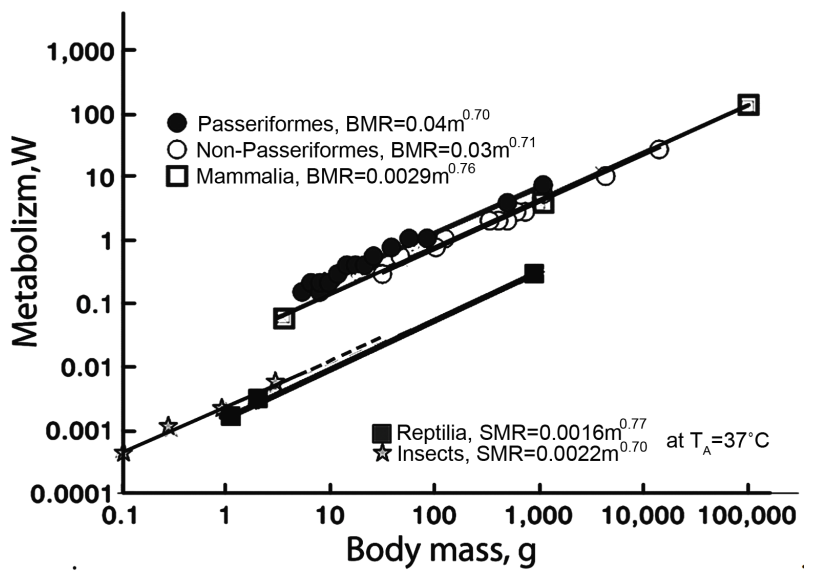

Figure 3. Relationships of resting metabolism $(B M R, S M R)$ to body mass in different group's of animals. 


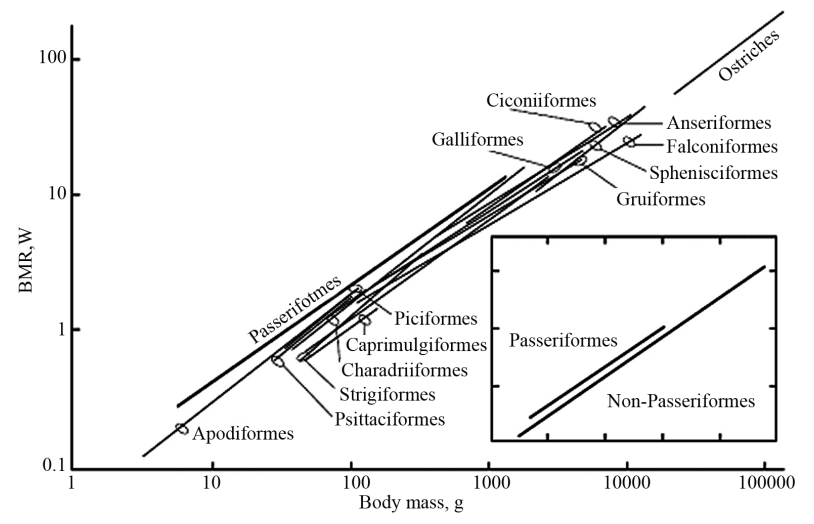

Figure 4. Relationships of basal metabolic rate $(B M R, \mathrm{~W})$ to body mass $(m, \mathrm{~g})$ in different orders of birds.

cording to the data tabulated by Gavrilov and Dolnik [52] and additional data for birds belonging to 16 orders, as well as a mixed group of Struthioniformes, Rheiformes, and Casuariformes, referred to as "ostriches."

A total of 687 species have been analyzed, including 352 Passeriformes, six Caprimulgiformes, five ostriches, and ten or more of the remaining orders; the regression lines are drawn from the minimal to maximal body masses of the species measured within an order.) A comprehensive integrated study of the energetics of passerine and non-passerine birds and its comparison 1000 with the energetics of mammals provides insight into the evolutionary, taxonomic, and ecological consequences of homoiothermy.

\subsection{Origin of Basal Metabolic Rate}

Basal metabolism is an area limited by minimal and maximal heat loss converging at $T_{\mathrm{A}}=T_{\mathrm{B}}$ and a line of $B M R$ level (Figure 2). It is a component, not dependent on $T_{\mathrm{A}}$, which provides for a transition from the minimal heat loss to the maximum. As is evident from the scheme in Figure 1, once the ability to change heat dissipation appears, the minimal metabolic capacity, or $B M R$, should inevitably emerge. Without $B M R$, the heat dissipation would merely decrease (or increase) at a certain rate, and switching to another activity mode would require a certain period of time, which is actually observed in poikilotherms, which must change their activity to a resting period rather rapidly. Thus, the $B M R$ level is the factor that determines the transition from one degree of heat conductance change to another, which, naturally, is important for the thermoregulation at rest, but has even greater significance in locomotor activity. This is why the periods of locomotor activity in homoiotherms may be very extended (just recollect that birds during their migrations are able to fly for up to several days without any rest) and easily alternate with rest periods, when the minimal metabolic activity is maintained and the transi- tion to locomotor activity is instant. A certain damper device that would quench the fluctuations in ambient temperature and provide an instant transition from rest to activity becomes necessary to stabilize the body temperature and ensure constant preparedness for activity.

In order to rapidly perform this transition, animals should have a certain component independent of the ambient temperature. $B M R$ is the component that plays this role, being an integral characteristic of physiological organization. Birds always display a certain minimal level of heat generation, which results from heat production in basic physiological processes that can be never arrested. This level of heat productionallows the body temperature to be maintained within a certain range, i.e., the so-called thermoneutral zone. What is the range of ambient temperatures where the $B M R$ level is sufficient to maintain a constant body temperature? It is natural that this level should damp certain average temperatures on Earth.

The average temperature on the earth surface is approximately $14^{\circ} \mathrm{C}$ and, for a relatively long period, the mean maximal temperature continued to be about $33^{\circ} \mathrm{C}$ $35^{\circ} \mathrm{C}$. Therefore, it is reasonable to assume that the $B M R$ level should support animal existence in the range of 14 to $33^{\circ} \mathrm{C}-35^{\circ} \mathrm{C}$ without any additional expenditure for thermoregulation. The thermoneutral zone of the nonpasserine birds with a mass of $1 \mathrm{~kg}$ falls into the range of $14^{\circ} \mathrm{C}-35^{\circ} \mathrm{C}$, that is, their $B M R$ is able to damp the fluctuations of ambient temperatures from the mean $T_{\mathrm{A}}$ of the earth surface to the mean maximal temperature continuing for a relatively long period. This is indirect evidence for the fact that the first birds were of this particular size, as has been confirmed by paleontological and morphological data (Brodcorb, 1971). It is important to emphasize that, although this reasoning is based on a certain global approach, both at that time and now, the range of $14^{\circ} \mathrm{C}$ to $33^{\circ} \mathrm{C}-35^{\circ} \mathrm{C}$ is the most optimal for homoiotherms. Moreover, there are no precise data in the area of the Earth where the first homoiotherms appeared; however, it is more or less clear that this took place not at high latitudes and that the mean maximal temperature, which continued for a relatively long period of time in the area where homoiotherms originated and lived, did not exceed $33^{\circ} \mathrm{C}-35^{\circ} \mathrm{C}$, which is very important for the establishment of a constant body temperature.

\subsection{Why Homoiothermy Originated with Just the Same Body Temperature?}

The results demonstrate (Figure 5; top panel, the same model as in Figure 1) that an animal's existence in the temperature range of $T_{\mathrm{A}}=T_{\mathrm{uc}}$ to $T_{\mathrm{A}}=T_{\mathrm{B}}$ is only possible at the expense of water evaporation, which continues to increase at $T_{\mathrm{A}}>T_{\mathrm{B}}$. Naturally, both $T_{\mathrm{uc}}$ and especially $T_{\mathrm{B}}$, 

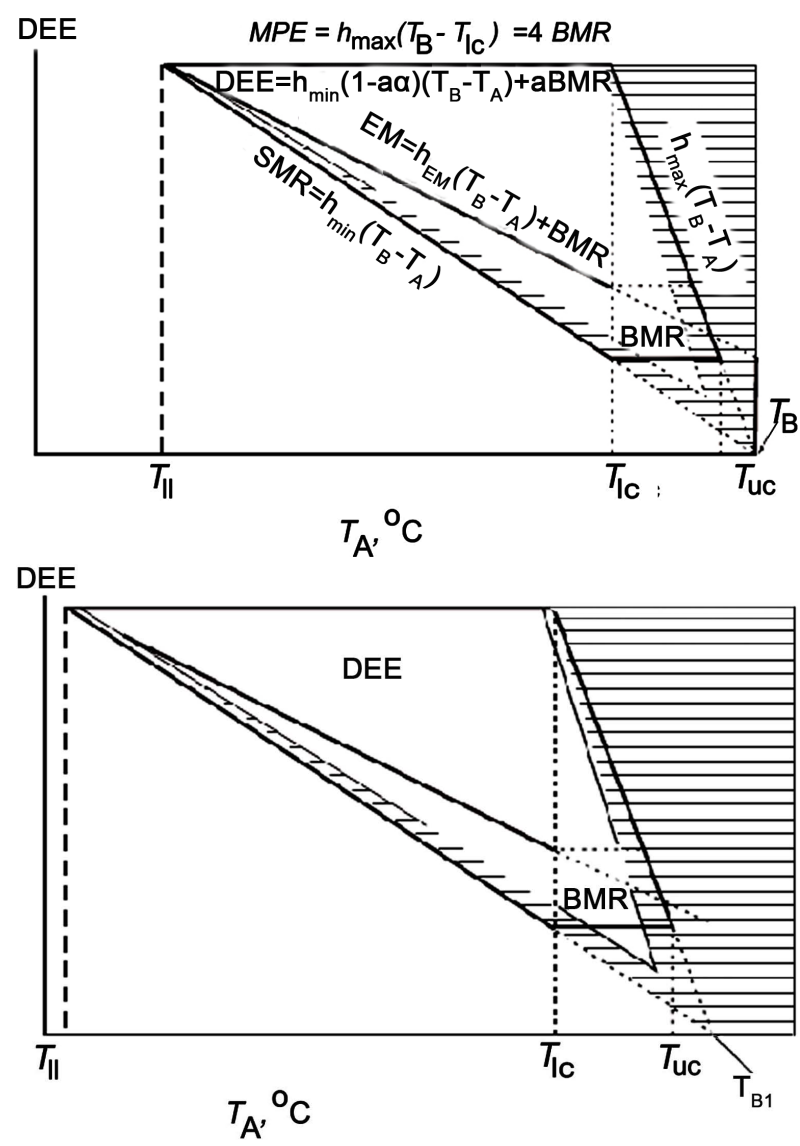

Figure 5. Illustration explaining why homoiotherms could not have a lower body temperature (TB). Top panel: same model as in Figure 1. Bottom panel: TB is arbitrarily decreased by approximately $10^{\circ} \mathrm{C}$. See text for explanations.

should certainly be higher than a high ambient temperature continued for a fairly long time. If $T_{\mathrm{B}}$ is lower than the high ambient temperature that continues for a relatively long time, all productive work is nearly impossible, since all energy will be spent on water evaporation in order to maintain body temperature. For average conditions on the Earth, both now and in the Mesozoic, when homoiotherms emerged, this long-term high $T_{\mathrm{A}}$ value amounts to about $35^{\circ} \mathrm{C}$. Consequently, the $T_{\mathrm{B}}$ of homoiotherms should inevitably be higher than $35^{\circ} \mathrm{C}$, so that these animals could have the possibility to dissipate at least some amount of energy via their body covers; moreover, it is more beneficial to have the highest body temperature possible. However, the limit $T_{\mathrm{B}}$ value is determined by the biochemical properties of proteins, rather than pure energetics. This is why the $T_{\mathrm{B}}$ of mammals is $37^{\circ} \mathrm{C}$ (except for Monotremata, which have a $T_{\mathrm{B}}$ of $32^{\circ} \mathrm{C}$, which may be associated with their origin in Cretaceous Australia, where the ambient temperature did not exceed $30^{\circ} \mathrm{C}$ ), while that of passérines is about $40^{\circ} \mathrm{C}$. In other words, homoiothermy could not have originated via a stepwise increase in body temperature and no ho- moiotherms with body temperatures of $15^{\circ} \mathrm{C}, 20^{\circ} \mathrm{C}$, or $30^{\circ} \mathrm{C}$ could have existed if the temperature on the Earth (in the area where homoiotherms emerged) exceeded these values for at least one season over a relatively long period. Assuming that a certain homoiotherm has a body temperature that is approximately $10^{\circ} \mathrm{C}$ lower, say $25^{\circ} \mathrm{C}$ (see bottom of Figure 5, where the $T_{\mathrm{B}}$ is arbitrarily decreased by approximately $10^{\circ} \mathrm{C}$ ), the entire temperature region appropriate for living shifts towards low temperatures and existence at temperatures typical on Earth, $20^{\circ} \mathrm{C}-35^{\circ} \mathrm{C}$, becomes impossible because significant water expenditures are needed to maintain constant $T_{\mathrm{B}}$ when is its lower than or equal to the ambient temperature (Figure 5, bottom panel).

\subsection{Erythrocytes in Birds and Mammals: How to Explain the Difference in the Structure}

In mammals, erythrocytes are enucleate biconcave cells versus larger nucleated cells in birds. These differences in the shape and volume also influence the ability of hemoglobin to bind and release oxygen. The metabolic intensities and, correspondingly, the oxygen consumption rates in birds and mammals both at rest and in activity are $10-16$ times higher than in poikilotherms of the corresponding masses (Figure 3), but are likely to be attained in birds and mammals in different ways. Mammals, which had developed an aerobic metabolism, emerged in the Triassic, when the oxygen content in the atmosphere was by approximately $50 \%$ lower than the current level and even lower than in the Jurassic period (Figure 6) [53,54]. A drastic decrease in the total content and percentage of oxygen in the Triassic was connected with the prevalence of arid conditions on the continents [53]. Under these conditions, mammals got rid of the nuclei in erythrocytes (having obtained enucleate and biconcave cells, where the surface area of the contained hemoglobin was larger), which led to thinner capillaries, while the biconcave shape provided a larger exchange area. Birds, which originated from more advanced reptiles, had established powerful respiratory and circulatory systems and, since they emerged at the time when the oxygen content in the Earth atmosphere approached the present level, had no need to eliminate the nuclei from their erythrocytes.

\subsection{Aerobic Supply of Activity, Sensory Systems and Develop of the Brain}

Intensive blood aeration and high body temperature created the necessary conditions for rapid neural responses and formed a prerequisite for the expansion of the behavioral repertoire. The high activity and, as a conesquence, fast and distant migration in space should be provided by the development of the ability to orient in 


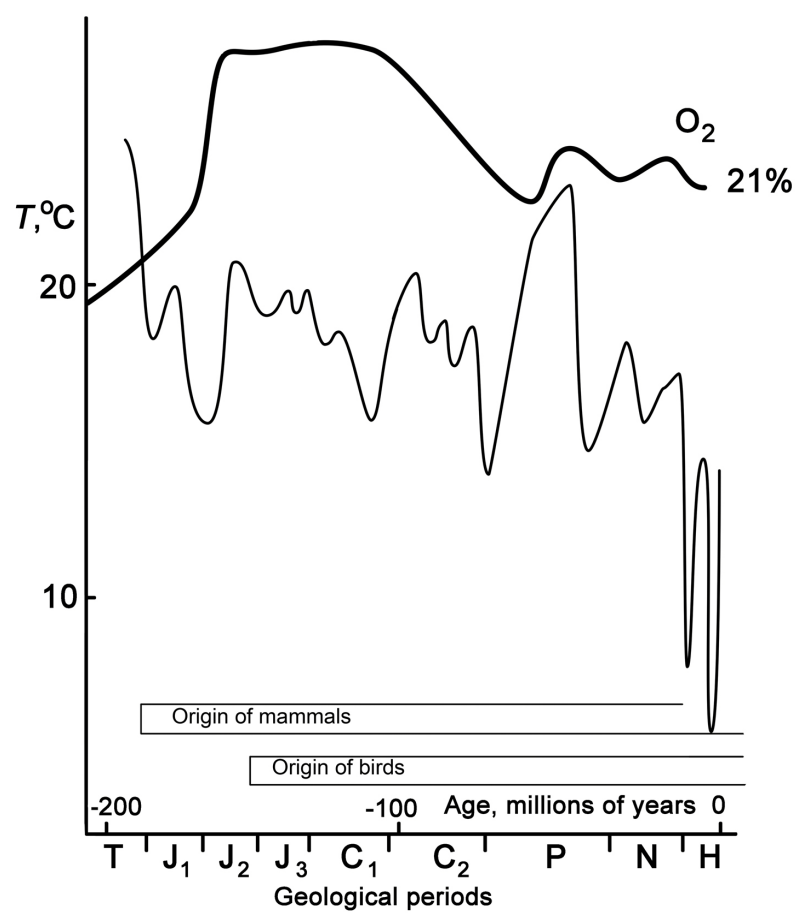

Figure 6. The change of oxygen content in the atmosphere and ambient temperatures of Earth in different geological periods (according to. [54]).

space, which is essential for mobile animals. Orientation requires the enhanced development of various sensory systems, first and foremost, auditory and visual ones. The maturation of these sensors, the level of their development, their state, and the functional characteristics in bird ontogenesis strictly correlate with the establishment of homoiothermy. An efficient thermo regulation, with a sufficient oxygen supply to the developing sensors, allows a juvenile to adequately analyze the ambient parameters [55]. Experimental data suggest that the functional significance of the increase in passerines) and at the level of the individual, should appear as an increase in the work output; lead to an increase in the maximal $M E$ and potential productive energy; and, as a consequence, to an increase in the productivity (see Figure 2). Thus, natural selection stimulates an increase in the rate of energy metabolism via the control of productive energy balance, that is, an increase in the energy balance towards the energy spent for productive processes and behavior (growth, reproduction, molting, migrations, etc.), as well as for the basic physiological processes underlying the existence of the organism and the possibility of productive activity. An increase in the productive energy balance is attained via the progressive complication of organization, which, on one hand, elevates the energy expenditures for basic physiological processes and, on the other hand, increases the productive energy. Another important fact is the establishment of the mini- mal metabolic capacity, which, on one hand, determines other characteristics of the energetic capacity and the level of work output in homoiotherms (this follows from experimental Equation (3) as follows: $D W O=h_{l}(1-$ $\left.a \alpha)\left(T_{\mathrm{B}}-T_{\mathrm{A}}\right)+a \alpha B M R\right)$ and, on the other hand, allows an instant transition from rest to activity. It is impossible to describe all consequences of the emergence of homoiothermy. However, it is important to clearly understand that everything that we have in higher vertebrates is its result. Homoiothermy and, as a consequence, a high aerobic metabolism, had enhanced accelerated development of the sensory systems and brain (Figure 7). The development of sensory systems and brains allowed behavior to reach a new level and become more complex. Note that the brain mass in the bony fish, which have no problem with oxygen supply due to their bronchial respiration, is even higher than in reptiles (Figure 7).

An increase in the aerobic capacity and the need of stable temperature conditions in order for the nervous system to function in complex behavior patterns were major selective factors in the establishment of homoiothermy; this is what provided for the metabolic and sensory support of the elevated activity. Birds (and mammals) display a higher level of aerobic metabolism, which is sufficient to provide for complex behavioral patterns that are unfeasible for lower vertebrates. In addition, their homoiothermic state, as well as high and stable body temperature, allows them to avoid the decalerating effect of cold temperatures on both the metabolic support of their behavior and the metabolic level. Independently of definition, behavior is the interaction between an animal and the ambience, that is, first and foremost, its locomotor activity. In this interaction, both the basic and intermediate metabolic rates are changed, as well as the neurosecretory, humoral, and emotional statuses and the work intensity of the sensory systems. All of these processes require an adequate oxygen sup-

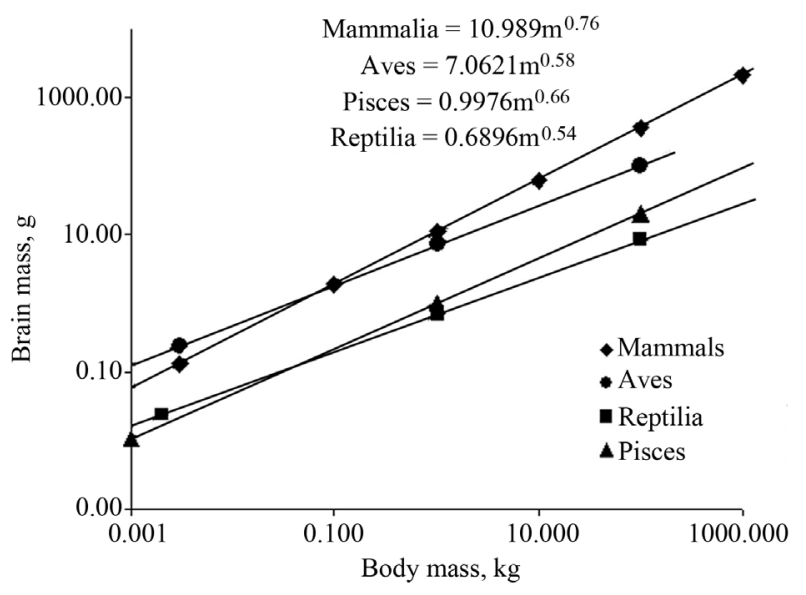

Figure 7. Relationships of brain mass to body mass in four classes of vertebrates (according to [5]). 
ply. Correspondingly, any complex goal-oriented behavior is only feasible in the presence of aerobic metabolism.

\subsection{Consequence of Homoiothermy: Minimal Size, and Parental Care}

The next most important consequence of homoiothermy is that it led to an increase in the minimal size of birds and mammals. There can be no homoiotherms with weights smaller than $3 \mathrm{~g}$, whereas the body mass of the smallest gecko lizards, Sphaerodactylus parthenopion and $S$. ariasae, is $1.5 \mathrm{~g}$. These geckoes, as well as some frogs, are the smallest terrestrial vertebrates on Earth. The size difference between the adults and newborns (or just hatched individuals) is also considerably smaller in homoiotherms. Calculations show that the mass of bird hatchlings cannot be smaller than the adult weight divided by 32 ; this result of homoiothermy follows from the equations $h \max =4 h_{\min }$ and $M P E=4 B M R$. The same correspondence (except for the marsupials and some large predators) is also true for the mammals. This is an important result of homoiothermy, which allows birds and mammals to include parental care in their development. Evidently, the degree of parental care increases from amphibians and reptiles to birds and mammals.

As is known, a wide range of ontogenetic patterns with two polar variants, precocial and altricial, is characteristic of birds. The brain of the adult precocial birds is smaller in a statistically significant manner compared to altricial birds; on the other hand, the newly hatched altricial birds have smaller brains than precocial birds. During the postnatal ontogenesis, altricial birds, in many respects via training, not only catch up with precocial birds in the brain mass, but even considerably exceed them [56]. The brain mass of the adult altricial birds exceeds that of the precocial birds in a statistically significant manner.

\subsection{Mesozoic Period and Prerequisites for Origination of Homoiothermy and Homoiotherms}

The specifics of the boundary between the Permian and Triassic periods saw significant changes in terrestrial vertebrate fauna. The prevalent reptile groups in the Permian period were theriomorphic reptiles and cotylosaurs, whereas the groups with diapsid skulls (lepidosaurs and archosaurs), united under the name "sauropsids," remained rather few in number. This balance had drastically changed by the beginning of the Mesozoic period. Of all the cotylosaurs, only procolophons (disappeared by the end of the Triassic) succeeded in passing to the Triassic period and, of the theriomorphic reptiles, only a few groups of dicynodonts and higher theriodonts carried over. However, the abundance and diversity of diapsid reptilians constantly increased, and they became dominant in the second half of the Triassic period [57]. Robinson (cited according to [57]) proposed a hypothesis that related the changes in reptilian fauna of the Triassic period to the specific physiological features of sauropsids and theriomorphic reptiles, which, to a certain degree of probability, can be estimated according to the corresponding characteristics of the extant descendants of both groups. The set of adaptations to the life under the conditions of a hot arid climate is characteristic of the currently existing sauropsids (in a broad sense, this term is used to unite all extant groups that belong to the class of reptiles and birds). Sauropsids are able to withstand considerably higher temperatures compared to the descendants of theriomorphic reptiles, mammals. The end product of the protein metabolism in sauropsids is uric acid, versus urea in mammals. Uric acid can form oversaturated solutions; correspondingly, its excretion from the body requires an approximately tenfold smaller amount of water compared to urea. Evidently, the excretory system of sauropsids saves water for the body considerably more efficiently than in mammals.

The Permian glaciations and the subsequent global warming led to a considerable change in the general appearance of the flora. The ancient club mosses, which is typical of the forests of the second half of the Paleozoic period, disappeared along with pteridosperms and cordaits. These mosses were replaced by various representatives of other gymnosperms, such as cycads, ginkgoes, and conifers. These species mainly formed the general appearance of the forests in the first half of the Mesozoic period.

The origin of homoiotherms dates back to the Mesozoic period. The Mesozoic was the era of tectonic, climatic, and evolutionary activities. The major outlines of modern continents were formed at that time, as well as the mountains at the peripheries of the Pacific, Atlantic, and Indian Oceans. The separation of the terrestrial part of the globe enhanced the speciation and other most important evolutionary events. During this entire period, the climate was exclusively warm; the first half of this period was drier, while the second half was more humid. Furthermore, some chilling periods took place in the late Jurassic and the first half of the Cretaceous, and pronounced warming took place in the mid-Cretaceous (the so-called Cretaceous temperature maximum); at approximately the same time, the equatorial climatic belt was formed $[58,59]$. The specific climatic features of the Mesozoic period played an important part in the evolution and emergence of new animal species. By the end of this era, the majority of biological diversity had approached its current state [60]. Zherikhin [60] described 
the situation as follows: "Over several millions of years, i.e., during the first half of the Cretaceous, angiosperms replaced the majority of characteristic mesophytic plants in paleontological deposits. At the same time, the mesophytic groups that escaped extinction, ferns and conifers, change in order to acquire an appearance similar to the modern one. Animals also undergo changes concurrently with plants. By the end of the early Cretaceous, the most ancient known eutherians were found and resembled the extant tenrecs of Madagascar (a kind of hedgehog). Birds became numerous and the first snakes emerged in the mid-Cretaceous, while the composition of insects changed drastically. In particular, ants appeared, and termites and butterflies became numerous. Multitudes of bony fish emerged in the sea.

Since that time, all of these animal groups, together with angiosperms, belong to the most important species that determine the face of nature." Mammals have been known since the Triassic period and birds have been since the Jurassic period; some of the Triassic and Jurassic findings can be ascribed to mammals and birds [6164]. Consequently, we must consider them to be homoiotherms, presumably with imperfect homoiothermy. Under Triassic and Jurassic conditions with a prevalence of mesophytic vegetation and low productivity of communities, the homoiothermy of birds and mammals could not provide them with ecological niches with the necessary energy flow, to say nothing of the possibility to increase their diversity. Small primitive forms of the most ancient mammals were approximately rat-sized and could not seriously compete with the flourishing reptilian fauna, which rich was rich in large, even giant forms. Having appeared at a relatively late stage of life, in a manner, mammals and birds occupied places that had been empty; moreover, their considerably higher energy demands required corresponding food potential. The emergence of homoiothermy (first and foremost, increase in the aerobic metabolism for the sake of increase in activity) dates back to the early and mid-Mesozoic; however, the biospheric conditions prevented the advantages of homoiothermy from being efficiently utilized until the late Cretaceous because of the absence of sufficient food potential. The energy channel necessary for development of homoiotherms only appeared with the emergence of angiosperms and the associated fauna in the mid-Cretaceous.

The progress of reptiles at that time was connected with the solution of two physiological problems, i.e., the establishment of true lung respiration and the emergence of an amniotic egg. The advantages of lung respiration require no comments. As for the amniotic egg, on the one hand, it has serious advantages over amphibian spawn, which allowed them to leave aquatic habitats. However, on the other hand, the egg is a factor that determined the size of the offspring, since the size of a youngster is limited by the maximal size of the egg; if the egg is too large, the shell will be crushed by the pressure of the liquid, whereas if the thickness of the shell is increased, the embryo will suffocate. In addition, a low metabolism and correspondingly limited food demand allowed for the rapid adaptive radiation of reptiles. At that time, reptiles entered the class of large animals (some dinosaurs with a mass to $60 \mathrm{t}$ are known). As for the egg, it remains (due to purely physical reasons) approximately the same size as that of the extant African ostrich (which has a body mass of about $100 \mathrm{~kg}$ and egg mass of about $2 \mathrm{~kg}$ ). Thus, it was difficult for the giant reptiles to nurse their offspring due to the difference in size between adults and youngsters. It is known that mainly large reptiles died off in the late Cretaceous; as for the fauna of, e.g., lizards, it changed earlier concurrently with insects and was less drastically affected by the late Cretaceous extinction [65, $66]$. For almost 130 million years, birds and mammals lived concurrently with the tremendous diversity of reptiles and, for a long time, could not utilize the opportunities of their homoiothermy and the advantages provided by the high activity and survivability because of the high energy consumption it entails and the impossibility to channel the necessary food sources.

Birds and mammals only started to occupy an appropriate position in biocenoses in the mid-Cretaceous. By the end of the Cretaceous, birds had lost their teeth and mammals were represented by both marsupials and eutherians. This is associated with the general evolution of the organic world, which, in the Mesozoic period, led to the emergence of flowering plants, which is considered to be the golden age of the associated invertebrate fauna, and a large diversity of flying insects. The emergence of angiosperms dates back to the early Cretaceous, while that of modern insects dates back to the mid-Cretaceous [65-67]. The emergence of flowering plants or angiosperms that were initially entomophilic, i.e., attracting insects for pollination, induced evolutionary changes in insects and the development of contemporary entomofauna, or the "angiospermization of the world" according to Ponomarenko [66]. This process involved all of the remaining components of the continental ecosystems and determined the fast spread of birds and therian mammals, as well as of bony fish in freshwater aquatic bodies. In the second half of the Cretaceous period, angiosperms colonized vast areas on land and represented an almost inexhaustible source of food $[67,68]$. The diversity of flowering plants stimulated the evolution of insects as their pollinators. The insects (especially flying ones) display a considerably higher activity compared to the reptiles that coexisted with them. Biocenoses changed with the emergence of angiosperms. The biomass of angiosperms increased, as well as the biomass of the asso- 
ciated invertebrates. The degree of mosaics in biocenoses increased as well. The natural succession of gymnosperm biocenoses was destroyed, leading to significant changes in the faunas $[41,69]$. Angiosperms more intensively take up many macro and trace elements. The corresponding result is a more advanced biological turnover, which allows for the more successful resistance to mineral starvetion. The role of the ability to take up calcium, which appeared in these plants, was of special importance, since this element started to accumulate in soils after plant death and neutralize the acid medium, thereby interfering with leaching. Since that time, it has become possible for highly fertile soils to be established and large amounts of biogeochemical energy to be accumulated [70,71]. The Mesozoic vegetation was poorly adapted to consumption by large terrestrial vertebrates [72] and prevented the emergence of herbivorous animals with high energy demands. In the Cretaceous period, the productivity of communities first decreased, then considerably increased with the colonization of new areas by angiosperms; moreover, both the plant entity and invertebrates contributed to this increase [73]. The angiosperms, presumably, grasses, produced a significant biomass that was rich in protein and fairly stable in its production level. The grasses provided for a considerable biomass of herbivorous organisms, which led to a drastic increase in the abundance of predators. After the spread of angiosperms in the mid-Cretaceous, leaf consumers, mainly miners (the insects living inside plants and "mining" tunnels there), emerged almost immediately. However, the actually massive consumption of green plant parts only commenced with the spread of cereal biomes. This gave rise to the ecosystems with a large volume of biomass comprising most diverse herbivorous forms, their predators and parasites, coprophages, and necrophages [72]. One more reason why the poikilothermic vertebrates could not consume the manifold increased amount of biomass is that they were adapted to feeding on other plants and that there were many predators among them, although some characteristics of their dentition suggest that certain dinosaurs attempted to adapt to eating angiosperms $[57,74]$. The mean daily energy expenditures for life-supporting activities measured under natural conditions at optimal ambient temperatures in extant animals by the doubly labeled water technique, the so-called "field" metabolic rate $(F M R, \mathrm{~W})$, suggest the following allometric dependences on the body mass $(m$, $\mathrm{kg})$ :

Reptilian $F M R=1.07 \mathrm{~m}^{0.89}[75]$;

Avian $F M R=3.36 \mathrm{~m}^{0.68}[75]$; and

Mammalian $F M R=8.91 \mathrm{~m}^{0.734}[75]$.

These equations demonstrate that the amount of energy spent by birds and mammals for their life-supporting activities is larger by one order of magnitude and, correspondingly, they consume more energy. We would like to emphasize that, of the overall reptiles, only ambush predators and a few herbivorous forms (manly of the small size cohort) succeeded in surviving to present day, and almost all of them are confined to warm habitats. On the other hand, homoiotherms have almost colonized the overall part of the biosphere appropriate for living, channeled new energy flows, and forced reptiles away from major niches. Thus, an increase in the amount of energy spent for common life activities gives a serious selective advantage.

Differences in metabolism are naturally reflected in the food consumption, which remains in the reptiles by over one order of magnitude lower compared to mammals and birds.

\subsection{Evolutionary Scenario of Origin and Development of Homoiothermy}

The emergence of homoiothermy and homoiotherms, with the primary intensification of their aerobic metabolism for the sake of increasing their activity, are dated back to the early and mid-Mesozoic period; however, the biospheric conditions prevented them from fully taking advantage of homoiothermy until the mid-Cretaceous period because of insufficient food resources. Only the advent of angiosperms and the associated invertebrate fauna provided the necessary energy channel for the development of homoiotherms. The so-called "mammalization" of theriodonts took place in the Mesozoic period [76]. Note here that the higher theriodonts displayed a number of progressive characters absent in sauropsids (for example, they were able to chew their food, which considerably increased the degree of its assimilation by the organism, which presumably had a hair cover, and so on). The "ornithization" of theropods took place at the same time [77]. Indeed, the fossils recently found in China and Mongolia suggest that feathered and, in some cases, flying animals had been formed in several different groups of theropods [77-79]. Certainly, these flying reptiles were not homoiotherms and their flight was a mere gliding that utilizes terrain features [22,80-83]. As the author sees it, plumage in different reptilian groups can be explained by attempts to regulate heat dissipation induced by overheating during activity, as well as to provide thermoregulation connected with the alternation of day and night, since these animals were relatively small. The morphophysiological basis of homoiothermy was provided by the evolutionary development of body systems associated with the blood circulation, respiration, and development of thermal insulation of body covers. All of these systems allowed for changes in heat dissipation without intensifying evaporation and the progress in homoiothermy with the obligatory establishment of basic 
metabolic capacity. The basic metabolic capacity enables homoiothermy to be maintained; however, its origin is connected with the need to maintain a high activity level, rather than the problems in thermoregulation. Thermoregulation is a side product of the increase in aerobic capacity in the establishment of homoiothermy. This episelective evolutionary mechanism is comprehensively described by A.S. Severtsov et al. [84].

The emergence of terrestrial vertebrates and the establishment of lung respiration, on one hand, and the advent of angiosperms and insects as food resources on the other demanded the enhancement of the overall animal organization. The author believes that a metabolic way of activity support, namely, an increase in the aerobic capacity, is the most significant result and simultaneously a prerequisite for the emergence of homoiothermy. The intensification of aerobic metabolism could develop by degrees in contrast to the development of the proper homoiothermy in the true sense.

Homoiothermy, with its obligatory aerobic maintenance of long-term activity, requires a constant minimal (basal) metabolic rate. $B M R$ was formed as a singular phenomenon and is historically connected with the metabolism in active behavior, rather than thermoregulation. The thermoregulatory muscle tone, which is the basis for chemical thermoregulation in birds and mammals, is lacking in reptiles. Presumably, the stepwise evolution of endothermy in the phylogenesis of birds and mammals led to a metabolic level equal to that developed by reptiles when running at a high temperature. This particular level had become the BMR for extant homoiotherms. For about 100 million years, birds and mammals were wallflower, rather than prevalent reptiles. Natural selection allowed animals with high-energy metabolisms to only increase their diversity and abundance when these (homoiothermic) animals could satisfy their substantially elevated demands for food resources. This took place in the mid-Cretaceous with the emergence of angiosperms and increase in the associated invertebrate fauna. The mid-Cretaceous period was a time of global crisis in the terrestrial biocenoses (Rasnitsyn, 1988). According to Zherikhin [85], “...the late Cretaceous insects differ most drastically from the early Cretaceous insections; how ever, Cenomanian faunas are already quite typical of the late Cretaceous and retain only a few archaic traits. Presumably, this change, which was the most rapid and drastic in the overall history of insects, was associated with the expansion of angiosperms at the end of the early Cretaceous." This is the approximate time when the ecological expansion of birds and mammals commenced, manifesting as adaptive radiation. The spread of angiosperms and insects as food resources able to satisfy the homoiotherms, but not the majority of reptiles, adapted to feeding on the preceding mesophytic flora and fauna, enhanced the ecological expansion of homoiotherms. Birds and mammals forced reptiles out of the major niches, colonized various habitats, and rapidly entered large size classes (mammals entered eight size classes and birds entered six). This was also assisted by a gradual decrease in the global temperature at that time. The fact that homoiothermy, which is a pronounced aromorphosis, smoldered for over 100 million years deep in the bosom of the biosphere, awaiting its time, is also worth special study. Two variants of explanation for this paradox are possible; i.e., either dinosaurs were actually homoiothermic, or the true homoiotherms (mammals and birds) only emerged in the Cretaceous. It is difficult to admit that homoiotherms, which possess a capacity that exceeds that of dinosaurs by one order of magnitude, did not manage to conquer a decent place in biocenoses. The mammals and birds of the Triassic and Jurassic periods were just trial rounds in the biosphere to create animals with developed aerobic capacity and constant (basal) metabolic rate, which enables an instant switch to activity.

The ecological advantages of animals that display a constant minimal (basal) metabolic rate are evident. $B M R$ renders the animal able to attain daily work output that is one order of magnitude higher than with a poikilotherm, as well as higher productivity. In turn, the basal metabolic capacity, or $B M R$, determines all the other levels of energy spending, maximal potential existence metabolism, maximal aerobic metabolism, and level of work output $[34,35]$. These particular energetic parameters determine the ecological potential of species and, correspondingly, their resistance to environmental factors. As a result, natural selection favors an increase in the energy expenditure for life-sustaining activities, since this considerably elevates the potential of productive work. However, these animals (homoiotherms) can exist only in ecological niches with large and constant energy flow, while niches with small energy flow remain empty, which provides the possibility for species with low energetic demands to successfully exist. High $B M R$ is unambiguously correlated with high productivity and high activity of an individual [86]. Individuals that display a high minimal capacity are able to yield high work output (males display high locomotor activity and females produce more eggs). Males with high $B M R$ have larger protected areas. A correlation between the work output and its result has been found; i.e., the individuals that spent more energy on reproduction yield better offspring [87]. There is also a correlation of reproduction success with the survival rate of the offspring and their energetics $[88,89]$.

\section{CONCLUSIONS}

We believed that the emergence of homoiothermy was 
directly associated with the development of high activity due to the aerobic metabolism. The standard metabolism of the extant birds and mammals is over one order of magnitude higher than poikilotherms of equal size. This high level of heat production, in combination with low heat conductance, is the basis for homoiothermy. Heat conductance is a result of the interactions between vasomotor and pilomotor responses. The differences in the level of heat production by one order of magnitude are presented, even when the body temperature of poikilotherms reaches the same values as in homoiotherms. The maintenance of homoiothermy is energetically expensive and requires considerably higher level of food consumption as compared with poikilotherms. It is rather unlikely that such an increase in metabolism develops in phylogenesis only for the sake of thermoregulation, especially at the earliest stages in the evolution of homoiothermy, when it is inefficient to maintain thermal stability. We believe that an increase in the aerobic capacity, which leads to an increase in activity, is the major selective factor that forms the background for the development of homoiothermy. The selective advantage of elevated activity may be considered to be a major condition for the survival and reproduction of homoiotherms. An advantage of birds and their ancestors with higher energetics can easily be explained in terms of selection; they are able to maintain higher flying speed and cover larger distances when searching for food and, in defensive behavior, will better protect their area and occupy new sites, as well as succeed in courting and reproduction. Despite an increase in the energetic cost for existence, these advantages are also important, since increased minimal capacity makes it possible to correspondingly elevate the energy input for meeting new energetic demands.

The emergence of homoiothermy with its aerobic provision for long-term activity and opportunities to regulate metabolic and heat-dissipation levels created many new prospects for birds. The achieved high level of long-term energy utilization is provided for longer activity, while its sensory support complicated and diversified the avian (and mammalian as well) behavioral repertoire, allowing them to colonize almost the entire part of the biosphere suitable for life (except for completely exotic habitats, e.g., abyssal).

Thus, the homoiothermy in birds and mammals originated independently and at different geological times. However, in both cases, it was formed as a side product of the selection for upgrading the aerobic metabolism, which provided an increase in activity. The advantages of high and stable body temperature, which is necessarily connected with an increase in metabolism, induced development of thermoregulatory adaptations, such as fur and plumage. This allowed the metabolically generated heat to be preserved and the heat absorption in hot ambience to be decreased. The capacities of the ventilation, respiratory, and enzymatic systems of extant reptiles are completely able to maintain the level of the homoiothermic metabolism at rest. The contemporary reptiles had considerably reduced aerobic limits and functional anaerobic system for the provision of a short-term activity $[24,90]$. The emergence of homoiothermy with the aerobic maintenance of long-term activity and the possibility to regulate the levels of the metabolism and heat dissipation created new vistas for homoiotherms. Attaining this level of long-term energy utilization made it possible to extend the activity period, and its sensory support complicated and diversified the avian behavioral repertoire, as well as that of mammals, and allowed them to colonize almost the entire part of the biosphere suitable for life. This was enhanced by including parental care into their ontogenesis, as well as transmitting the information accumulated during their lives to the offspring. It was assumed that some burrowing dinosaurs made attempts to nurse their offspring [91].

High levels of aerobic metabolism in birds and mammals have been attained in parallel in various groups of their reptilian ancestors. The level of homoiothermy when aerobic metabolism enables fairly long activity was formed in birds and mammals in different ways; they had different disjoined venous and arterial systems, nucleated or enucleate erythrocytes, and different lung structures that concurrently displayed equal minimal metabolic capacities and similar body temperatures, corresponding to the environmental conditions on Earth. It was difficult to believe that these metabolic changes occurred for strictly thermoregulatory purposes because the homeothermic animals originated in Mesozoic, the most thermally stable period in the Earth's history.

The basal metabolic rate in homeothermic animals is the fundamental scale of its energetic power and an indicator of the maximal level of the daily work output. The selective advantages of increased daily work output (or capacity for activity) effected by a high basal metabolism are not subtle but rather essential to survival and reproduction. An animal with a capacity for a greater work output has an advantage readily comprehensible in terms of selection. It can sustain greater levels of pursuit or flight when gathering food or avoiding becoming prey. It will be superior in territorial defense. It will be more successful in courtship and mating. This is because these enhanced capabilities give their owners the ability to increase its energy intake to meet new energy demands.

\section{ACKNOWLEDGEMENTS}

I am grateful to the researchers of the Department of Vertebrate Zoology of Moscow State University and its head, L.P. Korzun, for assistance and beneficial discussions, and to the Russian Foundation for 
Basic Research for long-term support of my work (last grants \# 11-0400992 and \# 12-04-01288). I separately thank T.B. Golubeva for valuable criticism, which allowed the manuscript to be essentially revised.

\section{REFERENCES}

[1] Scholander, P.F., Hock, R., Walters, V. and Irving, L. (1950) Adaptation to cold in arctic and tropical mammals and birds in relation to body temperature insulation, and basal metabolic rate. Biological Bulletin, 99, 259-271. doi: $10.2307 / 1538742$

[2] Gavrilov, V.M. (2006) Environmental, physiological and thermodynamic prerequisites and consequences of homeothermy in birds. The Development of Modern Ornithology in Northern Eurasia: Proceedings of XII International Ornithology Conference of North Eurasia, Izd. Stavropol, 76-95.

[3] Gavrilov, V.M. (1997) Energetics and avian behavior. In: Turpaev, T.M., Ed., Physioogy and General Biology Reviews, Harwood Academy Publication $\mathrm{GmbH}$, Amsterdam.

[4] Hemmingsen, A.M. (1960) Energy metabolism as related to body size and respiratory surface, and its evolution. Report of Steno Memorial Hospital (Copenhagen), 9, 1110.

[5] Peters, P. (1983) Ecological implication of body size. Harvard University Press, Cambridge. doi:10.1017/CBO9780511608551

[6] Dolnik, V.R. (1995) Time and energy resources in birds in nature. Nauka, St. Petersburg.

[7] Darveau, C.A., Suarez, R.K., Andrews, R.D. and Hochachka, P.W. (2002) Allometric cascade as a unifying principle of body mass effects on metabolism. Nature, $\mathbf{4 1 7}$, 166-170. doi:10.1038/417166a

[8] Else, P.L., Turner, N. and Hulbert, A.J. (2004) The evolution of endothermy: Role for membranes and molecular activity. Physiological and Biochemical Zoology, 77, 950958. doi:10.1086/422767

[9] Bennett, A.F. and Ruben, J.A. (1979) Endothermy and activity in vertebrates. Science, 206, 649-654. doi:10.1126/science.493968

[10] Bennett, A.F., Hicks, J.W. and Cullum, A.J. (2000) An experimental test of the thermoregulatory hypothesis for the evolution of endothermy. Evolution, 54, 1768-1773.

[11] Dolnik, V.R. (2003) Origin of homoiothermy: An unsolved problem. Zhurnal Obshchei Biologii, 64, 451-462.

[12] Bennett, A.F. (1976) Metabolism. In: Gens, C. and Dawson, W.R., Eds., Biology of the Reptilians, Academic Press, New York, 127-223.

[13] O'Conner, M.P. and Dodson, P. (1999) Biophysical constraints on the thermal ecology of dinosaurs. Paleobiology, 25, 341-346.

[14] Gillooly, J.F., Allen, A.P. and Charnov, E.L. (2006) Dinosaur fossils predict body temperatures. PLOS Biology, 4, 248-254. doi:10.1371/journal.pbio.0040248

[15] Barrick, R.E. and Showers, W.J. (1994) Thermophysiology of tyrannosaurus rex: Evidence from oxygen isotopes, Science, 265, 222-224. doi:10.1126/science.265.5169.222

[16] Fricke, H.C. and Rogers, R.R. (2000) Multiple taxonMultiple locality approach to providing oxygen isotope evidence for warm-blooded theropod dinosaurs, Geology, 28, 799-802. doi:10.1130/0091-7613(2000)28<799:MTLATP>2.0.CO; $\underline{2}$

[17] Seebacher, F. (2003) Dinosaur body temperatures: The occurrence of endothermy and ectothermy. Paleobiology, 29, 105-122. doi:10.1666/0094-8373(2003)029<0105:DBTTOO $>2.0 . C$ $\underline{\mathrm{O} ; 2}$

[18] Amiot, R., Wang, X., Zhou, Z., Wang, X., Buffetaut, E., Lecuyer, C., Ding, Z., Fluteau, F., Hibino, T., Kusuhashi, N., Mo, J., Suteethorn, V., Wang, Y., Xu, X. and Zhang, F. (2006) Oxygen isotopes from biogenic apatites suggest widespread endothermy in Cretaceous Dinosaurs. Earth Planet. Science Letters, 246, 41-48. doi:10.1016/j.epsl.2006.04.018

[19] Eagle, R.A., Tutken, T., Martin, T.S., Tripati, A.K., Fricke, H.C., Connely, M., Cifelli, R.L. and Eiler, J.M. (2010) Body temperatures of modern and extinct vertebrates from $13 \mathrm{c}-18 \mathrm{o}$ bond abundances in bioapatite. Proceedings of the National Academy of Sciences of USA, 107, 1037710382. doi:10.1073/pnas.0911115107

[20] Eagle, R.A., Tutken, T., Martin, T.S., Tripati, A.K., Fricke, H.C., Connely, M., Cifelli, R.L. and Eiler, J.M. (2011) Dinosaur body temperatures determined from isotopic (13c-18o) ordering in fossil biominerals. Science, 333, 443-445. doi:10.1126/science. 1206196

[21] McNab, B.K. (2009) Resources and energetics determined dinosaur maximal size. Proceedings of the National Academy of Sciences of USA, 106, 1-5. doi:10.1073/pnas.0904000106

[22] Pierson, D. (2009) The physiology of dinosaurs: Circulatory and respiratory function in the largest animals ever to walk the earth. Respiratory Care, 54, 887-911. doi: $10.4187 / 002013209793800286$

[23] Bennett, A.F. (1994) Exercise performance of reptiles. Advances in Veterinary Science and Comparative Medicine, 38B, 113-138.

[24] Bennett, A.F. and Lenski, R.E. (1999) Experimental evolution and its role in evolutionary physiology. American Zoologist, 39, 346-362.

[25] Bennett, A.F., Hicks, J.W. and Cullum, A.J. (2000) An experimental test of the thermoregulatory hypothesis for the evolution of endothermy. Evolution, 54, 1768-1773.

[26] Hicks, J.W., Wang, T. and Bennett, A.F. (2000) Patterns of cardiovascular and ventilatory response to elevated metabolic states in the lizard Varanus exanthematicus. Journal of Experimental Biology, 203, 2437-2445.

[27] Dolnik, V.R. (1998) The hypothesis of "warm-blooded" dinosaurs in the light of the energetics of modern animals. Uspekhi Sovremennoĭ Biologii, 118, 661-678.

[28] Dolnik, V.R. (1999) Allometric "arrangement" of reptile energetics. Zoologicheskii Zhurnal, 78, 1330-1339.

[29] Dolnik, V.R. (1999) Reconstruction of pterosaur energetics basing on the data on modern species energetics. 
Zhurnal Obshchei Biologii, 60, 359-375.

[30] Dolnik, V.R. (2002) Normal metabolism in vertebrates: What causes the differences between poikilothermic and homoiothermal classes? Zoologicheskii Zhurnal, 82, 643654.

[31] Seymour, R.S., Smith, S.L., White, C.R., Henderson, D.M. and Schwarz-Wings, D. (2011) Blood flow to long bones indicates activity metabolism in mammals, reptiles and dinosaurs. Proceedings of the Royal Society B, 0968.

[32] Gavrilov, V.M. (1995) Maximum, potentially productive, and normal metabolic levels of existence of passerines and non-passerine birds. 1. Dependence on the temperature of the environment, the relationship with the body weight, seasonal variations, and the relationship with other levels of energy consumption. Zoologicheskii Zhurnal, 74, 102-122.

[33] Gavrilov, V.M. (1995) Maximum, potentially productive, and normal metabolic levels of existence of passerines and non-passerine birds. 2. Relationship with the external work: Energy and environmental consequences. Zoologicheskii Zhurnal, 74, 108-123.

[34] Gavrilov, V.M. (1996) Basal metabolism of homoiothermal animals. 1. Power ratings and fundamental characteristic of energetics. Zhurnal Obshchei Biologii, 57, 325345.

[35] Gavrilov, V.M. (1996) Basal metabolism of homoiothermal animals. 2. The emergence in evolution, energy and environmental consequences. Zhurnal Obshchei Biologii, 57, 421-439.

[36] Gavrilov, V.M. (2000) How differences in basal metabolism affect energy expenditure on self-maintenance and energy efficiency in passeriformes and non-passeriformes. Doklady Biological Sciences, 371, 152-155.

[37] Gavrilov, V.M. (2000) What determines the mass-exponent factor of $3 / 4$ in the allometric equations of basal metabolism in homoiothermal animals? Doklady Biological Sciences, 371, 172-175.

[38] Gavrilov, V.M. (2013) Ecological, functional, and thermodynamic prerequisites and consequences of the origin and development of homoiothermy: A case study of avian energetics. Biology Bulletin Reviews, 3, 27-48. doi:10.1134/S2079086413010040

[39] Zherikhin, V.V. (1978) Razvitie i smena melovykh i kainozoiskikh faunisticheskikh kompleksov (trakheinye $\mathrm{i}$ khelitserovye) (The development and change of the cretaceous and cenozoic faunal assemblages (tracheata and chelicerata). Trudy PIN AN SSSR, 165, 189-223.

[40] Rautian, A.S. and Zherikhin, V.V. (1997) Models of phylocenogenesis and the lessons of environmental crises of the geological past. Zhurnal Obshchei Biologii, 58, 2047.

[41] Zherikhin, V.V. and Rautian, A.S. (2000) Crises in the biological evolution. Nauka, Moscow.

[42] Gavrilov, V.M. (2011) Energy expenditures for flight, aerodynamic quality, and colonization of forest habitats by birds. Biology Bulletin, 38, 779-788. doi:10.1134/S1062359011080024

[43] Gavrilov, V.M. (2012) The fundamental avian energetics:
2. The ability of birds to change heat loss and explanation of the mass exponent for basal metabolism in homeothermic animals. Biology Bulletin, 39, 659-671.

[44] Gavrilov, V.M. (1994) General consistent patterns of the effect of temperature on the energetics of a homoiothermal animal (a case study of the great tit Parus major, Passeriformes, Aves). Doklady Akademii Nauk, 334, 121126.

[45] Gavrilov, V.M. (2001) Thermoregulation energetics of passerine and non-passerine birds. Ornitologiya, 29, 162182.

[46] Gavrilov, V.M. (2004) Comparative energetics of passerine and non-passerine birds: Size limits, energetic capacity, and environmental consequences. Ornitologiya, 31, 92-107.

[47] Suarez, R.K. (1996) Upper limits to mass-specific metabolic rates. Annual Review of Physiology, 58, 583-590. doi:10.1146/annurev.ph.58.030196.003055

[48] Brody, G. (1945) Bioenergetics and growth. Reinhold, New York.

[49] Dolnik, V.R. (1969) Bioenergetics of a flying bird. Zhurnal Obshchei Biologii, 30, 273-291.

[50] Kirkwood, J.K. (1983) A limit to metabolisable energy intake in mammals and birds. Part A: Physiology, 75, 1-3. doi:10.1016/0300-9629(83)90033-6

[51] Hoppeler, H. and Weibel, E.R. (2005) Scaling functions to body size: Theories and facts. The Journal of Experimental Biology, 208, 1573-1574. doi:10.1242/jeb.01630

[52] Gavrilov, V.M. and Dolnik, V.R. (1985) Basal metabolic rate, thermoregulation and existence energy in birds: World data. Acta XVIII Congressus Internationalis Ornithologici, 1, 421-466.

[53] Yanshin, A.L. (1997) How the air composition changes? Vestnik Rossiiskoi Akademii Meditsinskikh Nauk, 67, 108-113.

[54] Ivanov, V.D. (2000) Cretaceous biocenotic crisis. Soros. Obrazovat. Zhurnal, 6, 69-75.

[55] Golubeva, T.B. (1997) Type of ontogeny and speciesspecific stimulation in the development of auditory sensitivity in birds. Physiology and General Biology Revue, 12, 1-106.

[56] Stark, J.M. and Ricklefs, R.E. (1998) Patterns of development: The altricial-precocial spectrum. Oxford University Press, Oxford.

[57] Iordanskii, N.N. (2001) Evolyutsiya zhizni (Evolution of life). Akademiya, Moscow.

[58] Budyko, M.I. (1982) Izmeneniya okruzhayushchei sredy i smeny posledovatel'nykh faun (Environmental changes and consecutive fauna succession). Gidrometeoizdat, Leningrad.

[59] Krasilov, V.A. (1985) Melovoi period. Evolyutsiya zemnoi kory i biosfery (Cretaceous period. The evolution of the earth's crust and the biosphere). Nauka, Moscow.

[60] Zherikhin, V.V. (1984) Ecological crisis-A precedent in the Mesozoic. Energiya, 1, 54-61.

[61] Ivakhnenko, M.F., Golubev, V.K., Gubin, Y.M., Kalan- 
dadze, N.N., Novikov, I.V., Sennikov, A.G. and Rautian, A.S. (1997) Permian and triassic tetrapods of eastern Europe. Trudy Paleontological Institute, 268, 216.

[62] Lopatin A.V. (2004) Early miocene small mammals from the north Aral Region (Kazakhstan) with special reference to their biostratigraphic significance. Paleontologicheskii Zhurnal, 38, 217-323.

[63] Falkowski, P.G., Katz, M.E., Milligan, A.J., Fennel, K., Cramer, B.S., Aubr, M.P., Berner, R.A., Novacek, M.J., and Zapo, W.M. (2005) The rise of oxygen over the past 205 million years and the evolution of large placental mammals. Science, 309, 2202-2204. doi:10.1126/science.1116047

[64] Wible, J.R., Rougier, G.W., Novacek, M.J. and Asher, R.J. (2007) Cretaceous eutherians and laurasian origin for placental mammals near $\mathrm{K} / \mathrm{T}$ boundary. Nature, 447, 1003-1006.

[65] Agadjanian, A.K. (1996) Models of phytohagy in mammals. Paleontological Journal, 30, 723-729.

[66] Rasnitsyn, A.P. (1988) The problem of global crisis of terrestrial biocenoses in the middle cretaceous. Nauka, Moscow.

[67] Ponomarenko, A.G. (1993) The key events in the evolution of the biosphere. Nauka, Moscow.

[68] Krasilov, V.A. (1985) Melovoi period. Evolyutsiya zemnoi kory i biosfery (Cretaceous period. The evolution of the earth's crust and the biosphere). Nauka, Moscow.

[69] Zherikhin, V.V. (2003) Izbrannye trudy po paleoekologii i filotsenogenetike (Selected papers on paleoecology and phylocenogenetics). Tovar. Nauch. Izd. KMK, Moscow.

[70] Gorshkov, V.G. (1985) Stability of biogeochemical cycles. Ekologiya, 2, 3-12.

[71] Perfilova, O.Y. and Makhlaev, M.L. (2009) Geokhimiya biosfery (Geochemistry of the biosphere). Krasnoyarsk Federal University, Krasnoyarsk.

[72] Ponomarenko, A.G. (1998) Paleontology and balances of biogeochemical turnovers. In: Ponomarenko, A.G., Rosanov, A.Yu. and Fedonkin, M.A., Eds., Ecosystem Reorganizations and Evolution of the Biosphere, PIN, Moscow, 9-14.

[73] Plotnikov, V.V. (1979) Evolyutsiya struktury rastitel'nykh soobshchestv (Evolution of the structure of plant communities). Nauka, Moscow.

[74] Eskov, K.Y. (1999) Istoriya zemli i zhizni na nei (The history of the earth and life on it). MIROS, Moscow.

[75] Nagy, K.A. (2005) Field metabolic rate and body size. The Journal of Experimental Biology, 208, 1621-1625. doi:10.1242/jeb.01553

[76] Tatarinov, L.P. (1976) Morfologicheskaya evolyutsiya teriodontov i obshchie voprosy filogenetiki (Morphological evolution of theriodonts and general problems of phylogenetics). Nauka, Moscow.

[77] Kurochkin, E.N. (2006) Parallel evolution of theropod dinosaurs and birds. Journal of. Zoology, 85, 283-298.

[78] Kurochkin, E.N. (2001) Novye idei o proiskhozhdenii i rannei evolyutsii ptits. Dostizheniya i problemy ornitolo- gii severnoi evrazii na rubezhe vekov (New ideas on the origin and early evolution of birds. Advances and challenges in ornithology in northern Eurasia at the turn of the century). Kazan State University, Kazan.

[79] Kurochkin, E.N. and Bogdanovich, I.A. (2008) On the origin of avian flight: Compromise and system approaches. Biology Bulletin, 35, 1-11. doi:10.1134/S1062359008010019

[80] Unwin, D.M. (2003) On the phylogeny and evolutionary history of pterosaurs. In: Buffetaut, E. and Mazin, J.-M., Eds., Evolution and Palaeobiology of Pterosaurs, Geological Society, London, 139-190.

[81] Lu, J.C., Azuma, Y., Dong, Z.M., Barsbold, R., Kobayashi, Y. and Lee, Y.N. (2009) New material of dsungaripterid pterosaurs (Reptilia: Pterosauria) from Western Mongolia and its palaeoecological implications. Geological Magazine, 146, 690-700. doi: $10.1017 / \mathrm{S} 0016756809006414$

[82] Unwin, D.M. and Bakhurina, N.N. (2003) The age of dinosaurs in Russia and Mongolia. Cambridge University Press, Cambridge.

[83] Lu, J., Unwin, D.M., Jin, X., Liu, Y. and Ji, Q. (2010) Evidence for modular evolution in a long-tailed pterosaur with a pterodactyloid skull. Proceedings of the Royal Society B, 277, 383-389. doi:10.1098/rspb.2009.1603

[84] Severtsov, A.S., Kreslavskii, A.G. and Cherdantsev, V.G. (1993) Tri mekhanizma evolyutsii. Sovremennye problemy teorii evolyutsii (Three mechanisms of evolution. Modern problems of the theory of evolution). Nauka, Moscow.

[85] Zherikhin, V.V. (1980) Insects in terrestrial ecosystems: The historical development of the insect class. Trudy PIN AN SSSR, 75, 189-223.

[86] Gavrilov, V.M. (1999) Ecological phenomena of passeriformes as a derivative of their energetic. Acta Ornithologica, 34, 165-172.

[87] Nagy, K.A., Gavrilov, V.M., Kerimov, A.B. and Ivankina, E.V. (1999) Relationships between field metabolic rate, basal metabolic rate and territoriality in passerines. Proceedings of the 22nd International Ornithological Congress, University of Natal, Durban, 390-400.

[88] Gavrilov, V.M., Kerimov, A.B., Golubeva, T.B., Ivankina, E.V., Ilina, T.A., Karelin, D.V. and Kolyaskin, V.V. (1996) Energetics, morphophysiological heterogeneity of individuals, and the population structure in birds. 1. Energetics, morphophysiological heterogeneity, and population structure in the great tits in Moscow Oblast. Ornitologiya, 27, 34-73.

[89] Gavrilov, V.M., Kerimov, A.B., Aleksandrov, L.I., Golubeva, T.B., Ivankina, E.V., Ilina, T.A. and Shishkin, V.S. (1996) Energetics, morphophysiological heterogeneity of individuals, and the population structure in birds. 2. Energy, morphophysiological heterogeneity of individuals, and population structure in flycatchers. Ornitologiya, 27, 74-97.

[90] Bennett, A.F. (1991) The evolution of activity capacity. The Journal of Experimental Biology, 160, 1-23. 
[91] Varricchio, D., Martin, A. and Katsura, Y. (2007) First trace and body fossil evidence of a burrowing, denning dinosaur. Proceedings of the Royal Society B: Biological Sciences, 274, 1361-1368. 